\title{
SUBSEASONAL WEATHER PREDICTION IN A GLOBAL CONVECTION-PERMITTING MODEL
}

\author{
Nicholas J. Weber and Clifford F. Mass
}

\author{
Four global, high-resolution, monthlong simulations highlight the potential \\ of convection-permitting modeling for improving simulated tropical \\ convection and global subseasonal weather prediction.
}

A ccurate weather prediction at subseasonal (weekly to monthly) time scales is vital to many societal functions, including the transportation, agriculture, and energy sectors. Unfortunately, many operational global numerical weather prediction (NWP) models do not reliably produce skillful deterministic predictions more than two weeks into the future (Li and Robertson 2015; Weber and Mass 2017). A potential source of error in these extended forecasts is the models' poor representation of convection, particularly in the tropics. Latent heat release associated with tropical convection is important for global

AFFILIATIONS: WeBER AND MASS-Department of Atmospheric Sciences, University of Washington, Seattle, Washington CORRESPONDING AUTHOR: Nicholas J. Weber, njweber2@atmos.washington.edu

The abstract for this article can be found in this issue, following the table of contents.

DOI:10.II75/BAMS-D-I8-0210.I

A supplement to this article is available online (10.1175/BAMS-D-18-0210.2)

In final form 15 January 2019

(C)2019 American Meteorological Society

For information regarding reuse of this content and general copyright information, consult the AMS Copyright Policy. prediction at subseasonal (and other) time scales because it influences extratropical weather through large-scale atmospheric teleconnections (Wallace and Gutzler 1981; Brunet et al. 2010). Thus, the poor simulation of tropical convection in contemporary global models can hamper subseasonal atmospheric prediction in both the tropics and extratropics.

Several studies have shown that current NWP systems struggle to properly simulate organized tropical convection (Brunet et al. 2010) and its observed intraseasonal (2-128 days) variability (Lin et al. 2006). In particular, the Madden-Julian oscillation (MJO), an eastward-propagating intraseasonal tropical convective phenomenon that significantly impacts global weather (Madden and Julian 1972; Zhang 2013), is represented poorly in many operational NWP models (Lin et al. 2006; Seo et al. 2009): specifically, its observed slow $\left(\sim 5 \mathrm{~m} \mathrm{~s}^{-1}\right)$ eastward-propagation speed, multiscale precipitation variability, and movement across the Maritime Continent (Weaver et al. 2011; Kerns and Chen 2014; Kim et al. 2014).

Many of the aforementioned deficiencies in simulated tropical convection can be linked to the coarse grid spacing (greater than $10 \mathrm{~km}$ ) in current operational global NWP models, which necessitates the use of convective parameterization to estimate 
the contributions of unresolved cumulus clouds to large-scale heating, mass, and moisture (Brunet et al. 2010). The importance of convective representation is suggested by the fact that operational models with more realistic cumulus parameterization schemes, like the European Centre for Medium-Range Weather Forecasts model, enjoy superior MJO representation and global forecast skill (Vitart 2014, 2017).

Convection-permitting models (CPMs), which run at high horizontal resolution (less than approximately $4-\mathrm{km}$ grid spacing), can explicitly resolve motions associated with deep convection and forego the use of convective parameterizations (Prein et al. 2015). Compared to typical low-resolution global models with parameterized convection, CPMs more realistically simulate $\mathrm{MJO}$ events, more accurately reproduce the diurnal cycle of rainfall, improve the distribution of tropical deep convection, and reduce unrealistic widespread light precipitation commonly associated with parameterized convection (Miura et al. 2007; Sato et al. 2009; Inoue et al. 2008; Holloway et al. 2012). Because of their high computational cost, CPMs can be prohibitively expensive to run for large spatial domains or extended time periods; for this reason, most experiments with explicitly simulated convection have utilized limited-domain models, "gray zone" resolution (4-9 km), and/or short ( $<7$ days) integration times. The convection-permitting simulations presented in this article circumvent these compromises, providing new insights into the benefits of CPMs.

This study evaluates the potential for global CPMs to improve simulated tropical convection and global subseasonal prediction. Results from four global, monthlong convection-permitting model integrations are presented, along with an evaluation of the impact of explicit convection on tropical precipitation, the MJO, and extratropical predictive skill in subseasonal numerical forecasts.

DATA AND METHODS. Simulations were performed using the National Center for Atmospheric Research (NCAR) Model for Prediction Across Scales (MPAS; Skamarock et al. 2012), which uses centroidal Voronoi tessellations, primarily hexagons, to discretize the globe into grid cells (Fig. ES1 in the online supplemental material; https://doi .org/I0.II75/BAMS-D-I8-02I0.2). Our experiments used a uniform global mesh with 3-km grid spacing (i.e., the hexagonal grid cell centroids are $3 \mathrm{~km}$ from one another), which is fine enough to resolve the important features of deep convection (Weisman et al. 1997; Prein et al. 2015). For each case, a coarser $15-\mathrm{km}$ simulation was also performed for comparison; these runs were identical to their $3-\mathrm{km}$ counterparts except that they applied a convective parameterization, emulating contemporary operational NWP models. The MPAS runs were integrated on the Cheyenne
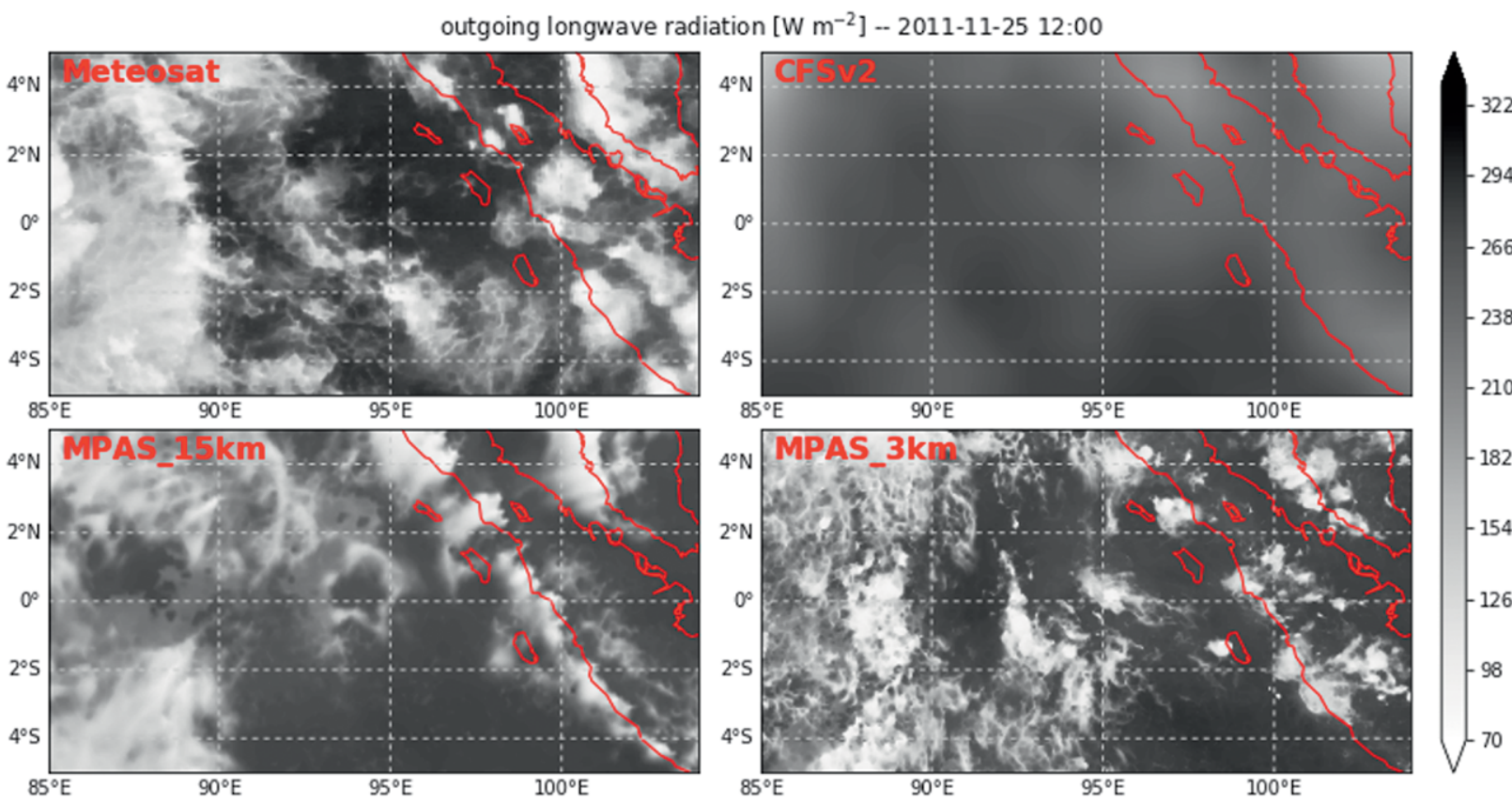

FIG. I. Outgoing longwave radiation $\left(\mathrm{W} \mathrm{m}^{-2}\right)$ from the combined infrared and water vapor channels of the Meteosat-7 satellite, the NWS CFSv2 forecast, the 15-km MPAS simulation, and the 3-km MPAS simulation, all valid at 1200 UTC 25 Nov 201 I (90-h lead time) over the eastern Indian Ocean and Sumatra. 
supercomputer at NCAR; each $15-\mathrm{km}$ run required roughly 80,000 core hours (and $\sim 8$ TB of disk space for model output), while each $3-\mathrm{km}$ simulation used roughly 2.8 million core hours ( $~ 80 \mathrm{~TB}$ of output).

All MPAS simulations implemented physics from the "convection permitting" suite provided in the MPAS, version 5.1, distribution. This suite includes two-moment, five-species Thompson microphysics scheme, the NOAA/NCEP-Oregon State University-Air Force Research Laboratory-NOAA/Office of Hydrology land surface model (Noah), MellorYamada-Nakanishi-Niino (MYNN) boundary layer and surface layer parameterizations, Rapid Radiative Transfer Model for global climate models (RRTMG) longwave and shortwave radiation schemes, Xu-Randall cloud fraction, and Yonsei University (YSU) gravity wave drag. For the $3-\mathrm{km}$ MPAS simulations, the convection scheme was turned off, while the $15-\mathrm{km}$ runs used the new Tiedtke cumulus scheme (Zhang and Wang 2017). The MYNN and YSU schemes are from version 3.6.1 of the NCAR Weather Research and Forecasting (WRF) Model, while the others are from WRF, version 3.8.1. The 2D Smagorinsky scheme was used for subgrid-scale mixing.

MPAS simulations were integrated for 28 days, with atmospheric initial conditions and oceanic boundary conditions from the National Centers for Environmental Prediction (NCEP) Final Operational Global Analyses. Sea surface temperatures were held constant at their initial value throughout each integration. The four cases evaluated here were chosen because they feature a variety of propagating MJO events and/or strong subseasonal circulation anomalies in the Northern Hemisphere midlatitudes. Three of our case studies included strong boreal winter MJO events that propagated across the Maritime Continent region, with initialization times at 0000 UTC 11 November 2011, 8 February 2013, and 2 December 2003 (case 1, case 2, and case 3, respectively). Case 1 encompasses the second MJO event observed during the Dynamics of the Madden-Julian Oscillation (DYNAMO) field campaign (Gottschalck et al. 2013). The fourth case (case 4), initialized on 8 December 2013, featured a strong, persistent extratropical ridge along the west coast of North America and a weak $\mathrm{MJO}$ in the eastern Indian Ocean.

MPAS forecasts were verified against Tropical Rainfall Measuring Mission (TRMM) 3B42 satellite precipitation estimates and Climate Forecast System Reanalysis (CFSR) atmospheric analyses. Additionally, the MPAS simulations were compared to those of the National Weather Service (NWS)
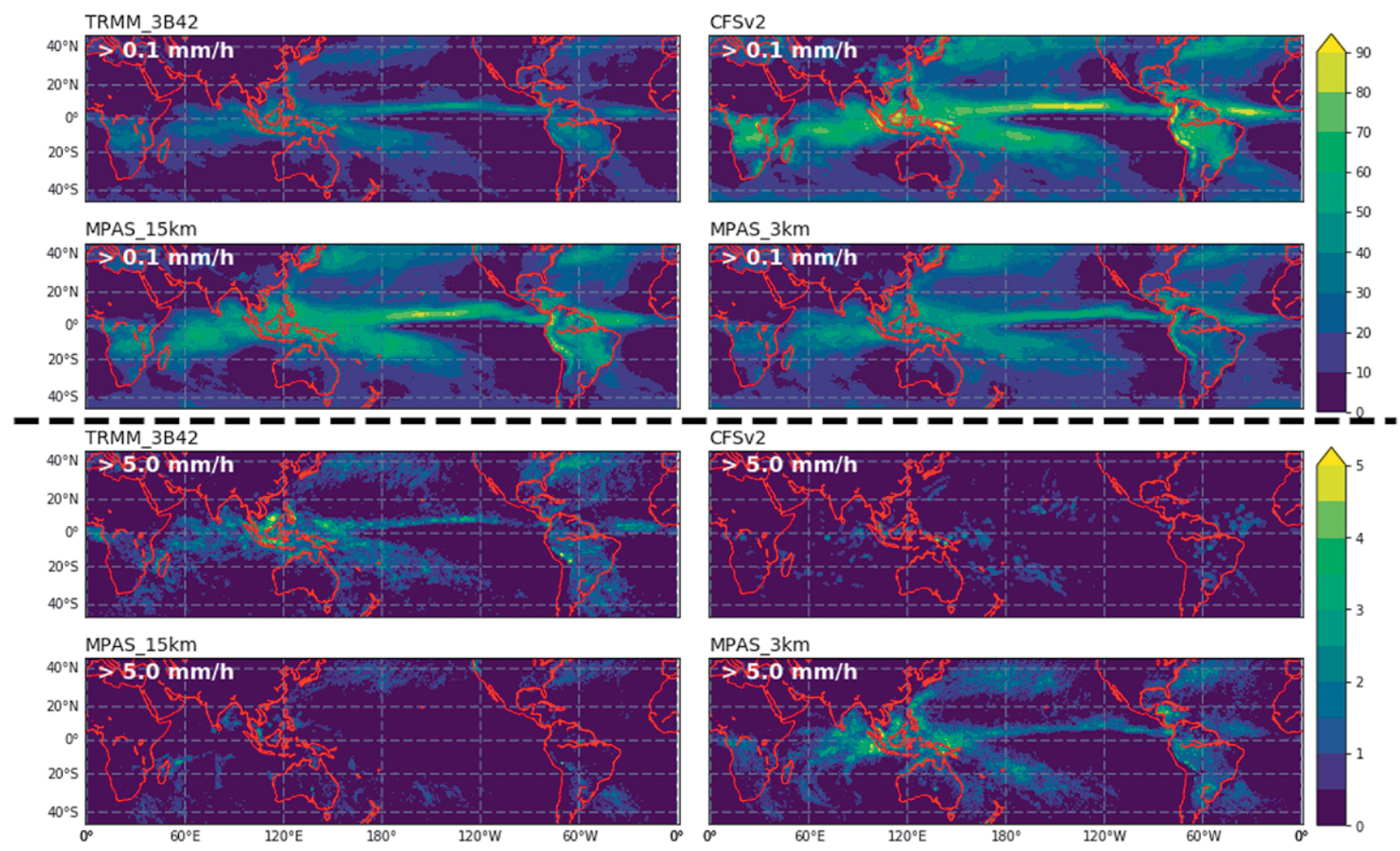

FIG. 2. Percentage of time during the four 28-day case studies of the precipitation rate exceeded (top four panels) $0.1 \mathrm{~mm} \mathrm{~h}^{-1}$ and (bottom four panels) $5.0 \mathrm{~mm} \mathrm{~h}^{-1}$ in the TRMM 3 B42 observational estimates and in the model simulations (CFSv2, MPAS_I5km, MPAS_3km). 

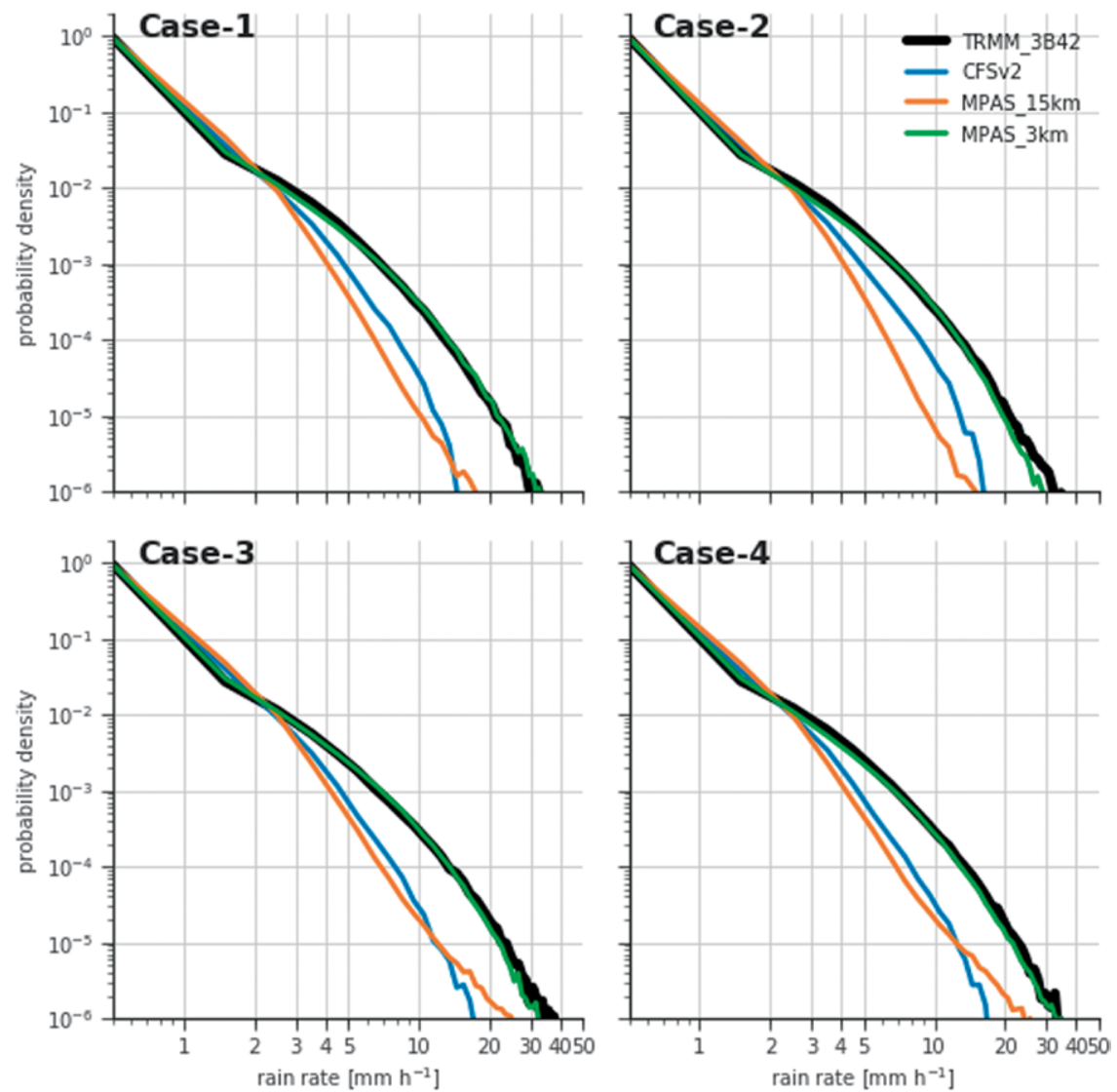

FIG. 3. Normalized precipitation rate frequency distributions for all four cases. The first day of each 28-day period is excluded from analysis to remove model spinup effects and only tropical $\left(15^{\circ} \mathrm{S}-15^{\circ} \mathrm{N}\right)$ grid points are considered. Rain rate data from TRMM (black), the CFSv2 forecast (blue), the 15-km MPAS simulation (orange), and the 3-km MPAS simulation (green) are shown. Axes are logarithmic.

Climate Forecast System, version 2 (CFSv2; Saha et al. 2014), an operational, coupled atmosphere-ocean model that utilizes convective parameterization, with a horizontal grid spacing of approximately $100 \mathrm{~km}$ and predictions out to nine months. The CFSv2 forecasts were initialized at the same times as the MPAS simulations for all cases.

RESULTS. Characteristics of tropical precipitation. The 3-km MPAS simulations realistically reproduced many important features of tropical convective clouds, including their multiscale organization, the diurnal cycle over land and ocean, and their organization into tropical cyclones (see Fig. ES2, an animation of outgoing longwave radiation from case 1). When compared to satellite observations (Fig. 1), the clouds simulated by the 3-km MPAS configuration exhibited similar finescale features (e.g., the small-scale flow features in the cirrus outflow of oceanic convection and mesoscale convective organization over land); the $15-\mathrm{km}$ MPAS output exhibits clouds that look overly smoothed, especially along the coastlines, while the relatively coarse NCEP CFSv2 forecast barely captures any cloud features. Aside from resolving finer-scale cloud features, another benefit of the convection-permitting configuration is the improved frequency of simulated light and heavy precipitation. Figure 2 shows that the 3-km MPAS simulations produced less frequent light precipitation (exceeding $0.1 \mathrm{~mm} \mathrm{~h}^{-1}$ ) and more frequent heavy precipitation (exceeding $5.0 \mathrm{~mm} \mathrm{~h}^{-1}$ ) when compared to CFSv2 and the 15-km MPAS run, which is more in accordance with the precipitation estimates recorded by TRMM.

Across the entire tropical belt, the CFSv2 and 15-km MPAS simulations, both of which employed convective parameterization, produced excessive light precipitation and insufficient heavy precipitation, while the $3-\mathrm{km}$ simulations closely matched the observation-derived distribution of rain rates (Fig. 3). In addition to improving the distributions of precipitation, the convection-permitting simulations exhibited a more realistic diurnal cycle of tropical precipitation (Fig. 4), more accurately simulating the observed timing of day/night extrema across all four cases. The timing of diurnal precipitation extrema was improved (i.e., delayed) by $2-3 \mathrm{~h}$ in each case. While both MPAS configurations exhibited a realistic diurnal amplitude over the ocean, both exaggerated the daytime maximum and underestimated nighttime precipitation over land, an issue that convectionpermitting resolution does not seem to alleviate. It is worth noting that improvements in the terrestrial diurnal cycle can also be achieved in coarser models by implementing more realistic cumulus parameterizations (Bechtold et al. 2014). 

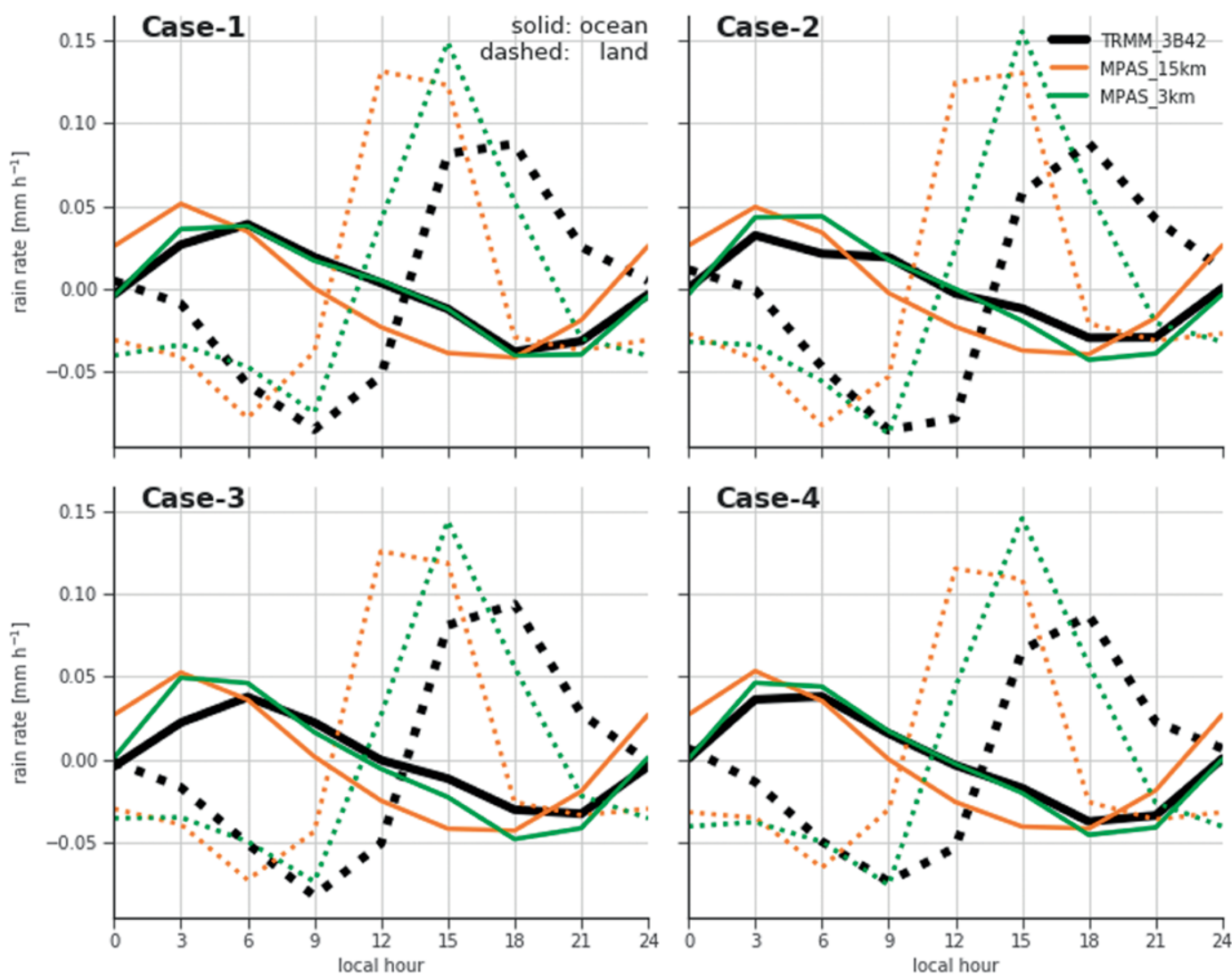

FIG. 4. Diurnal precipitation rate composites for all four cases. The first day of each 28-day period is excluded from all datasets to remove model spinup effects and only tropical $\left(15^{\circ} \mathrm{S}-15^{\circ} \mathrm{N}\right)$ grid points are considered. Rain rate data from TRMM (black), the 15-km MPAS simulation (orange), and the 3-km MPAS simulation (green) are shown. Solid lines show the diurnal cycle over ocean grid points and dashed lines represent the diurnal cycle over land. The mean of each diurnal composite was removed to avoid the inclusion of model mean state biases.

While many characteristics of tropical convection were improved in the $3-\mathrm{km}$ MPAS simulations compared to runs with parameterized convection, our $3-\mathrm{km}$ MPAS simulations produced roughly $5 \%-10 \%$ more total tropical precipitation than measured by the TRMM satellite (Fig. ES3). Most of this bias come from excessive precipitation in the Indo-Pacific warm pool region (not shown). Given that the rainfall rate frequencies are accurately produced in the $3-\mathrm{km}$ runs (Fig. 3), this overproduction of rainfall is possibly a symptom of unrealistically long-lived precipitating systems, a problem that may be ameliorated by coupling a CPM to an interactive ocean model (Hirons et al. 2018).

Representation of the MJO. Observational and forecast precipitation fields were averaged between $15^{\circ} \mathrm{S}$ and $15^{\circ} \mathrm{N}$ to examine the time-longitude behavior of precipitation features like the MJO. The observed MJO during case 1, characterized by two eastward-propagating waves between 22 November and 9 December (Gottschalck et al. 2013), was poorly captured by the CFSv2 forecast and entirely absent in the 15-km MPAS simulation (Fig. 5, first row). In contrast, the convection-permitting run faithfully captured the structure and propagation of these waves through 4 December, at which point the second simulated wave unrealistically "stalled" over the Maritime Continent. For case 2 (Fig. 5, second row), the eastward-propagating signal of the MJO was not appreciably improved in the $3-\mathrm{km}$ simulation, which, like the coarser MPAS run, featured primarily two westward-propagating waves around $\sim 80^{\circ}$ and $\sim 140^{\circ} \mathrm{E}$. The case $3 \mathrm{MJO}$ (Fig. 5, third row), on the other hand, was well captured in the convectionpermitting run, while the $15-\mathrm{km}$ MPAS simulation produced largely stationary convection. The MJO in case 4 (Fig. 5, fourth row) was less defined than in the other cases, but its broad area, slow propagation, and heavy Maritime Continent convection around 22 December were best captured in the 3-km run.

The intensity of the heavy MJO precipitation was more realistic in all four $3-\mathrm{km}$ simulations, whereas the precipitation in the other two models was generally too weak (consistent with Fig. 3). For all four 

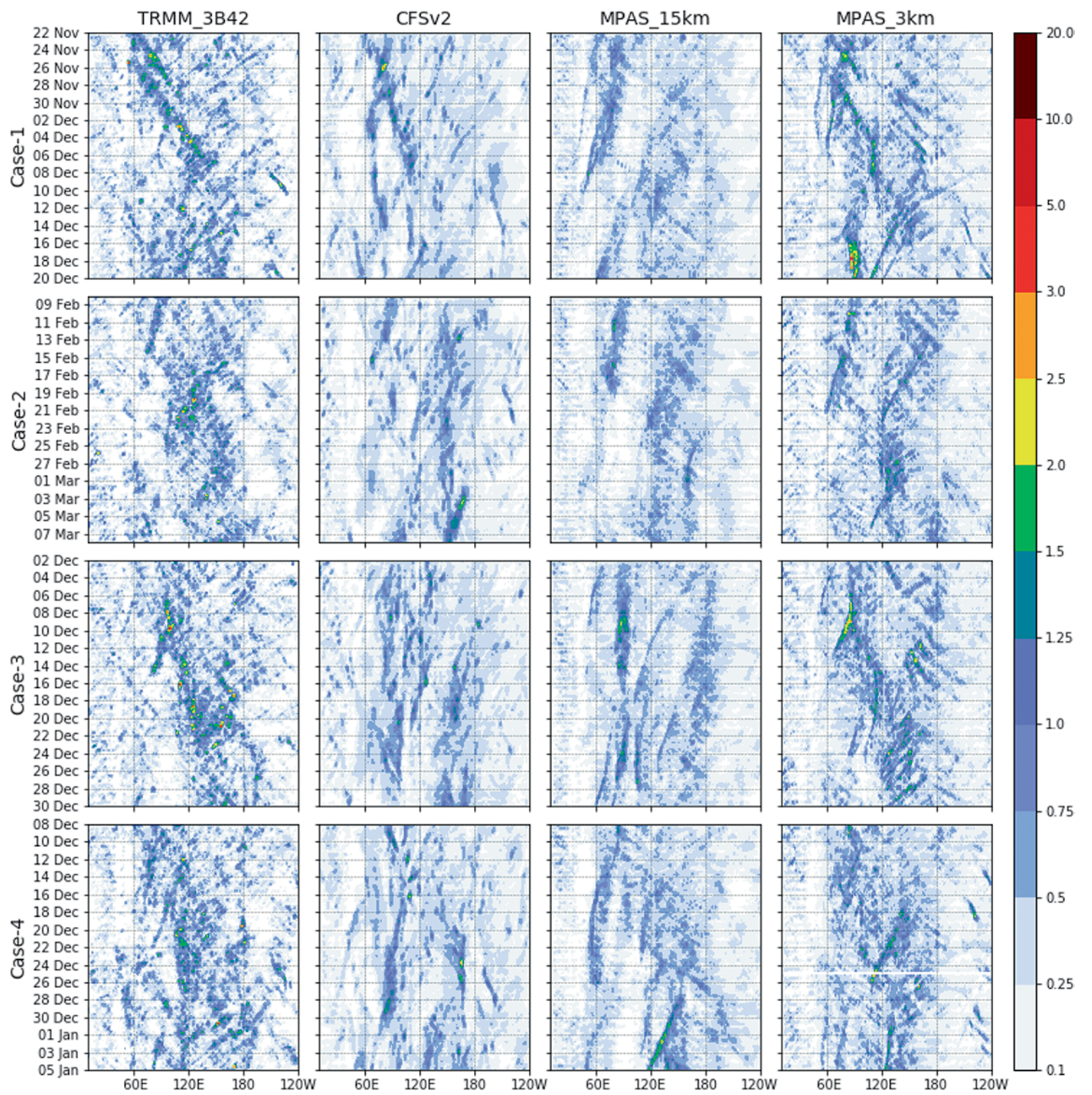

10.0

$-5.0$
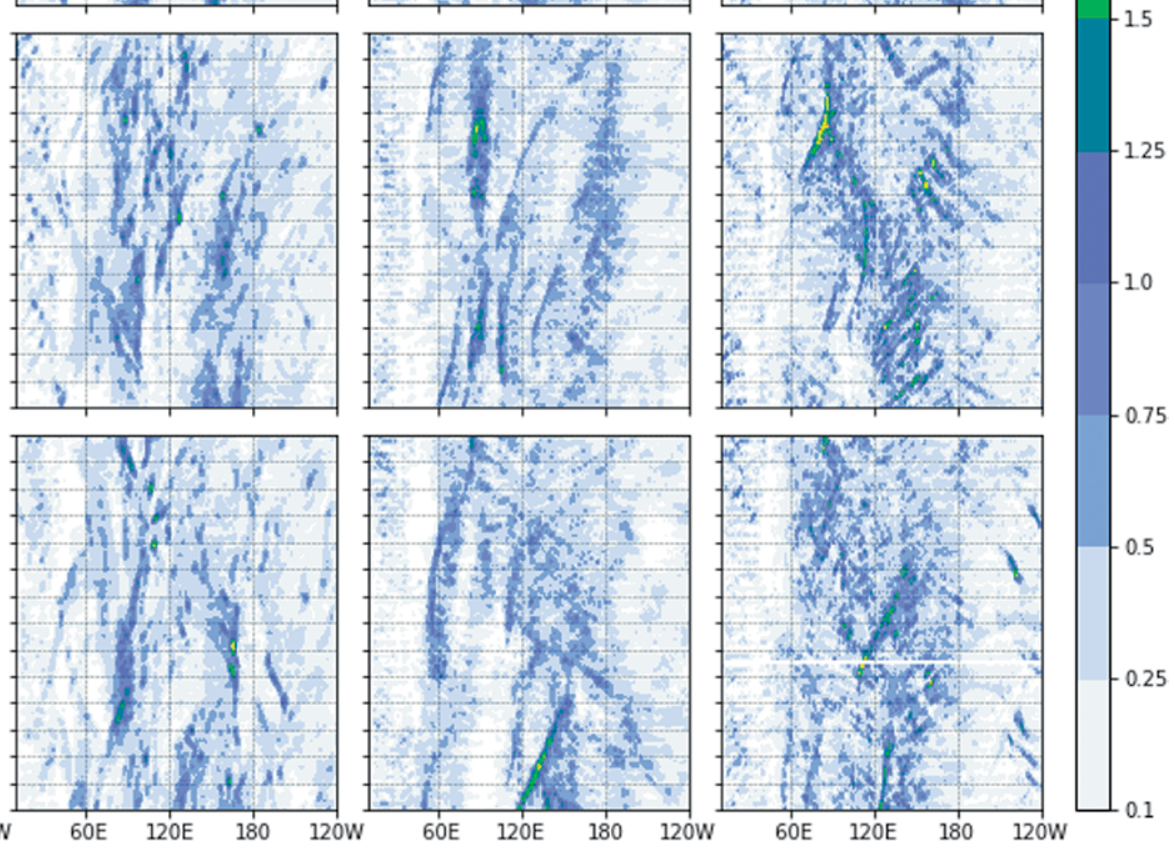

FIG. 5. Time-longitude (Hovmöller) diagrams of precipitation rate $\left(\mathrm{mm} \mathrm{h}^{-1}\right)$ averaged between $15^{\circ} \mathrm{S}$ and $15^{\circ} \mathrm{N}$ during each of the four cases. Precipitation data are from the TRMM 3B42 satellite product, CFSv2 reforecasts, I5-km MPAS simulations with parameterized convection, and the 3-km MPAS simulations with explicit convection.

cases, the 15-km MPAS configuration favored stationary or westward-propagating convection, generally associated with equatorial Rossby waves, over eastward-moving signals. The zonal winds associated with the MJO, characterized by low-level (upper level) convergence (divergence) accompanying the convection, are shown in Figs. ES4 and ES5; in general, the 3-km MPAS simulations better capture the eastwardpropagating signals, in accordance with the improvements noted in Fig. 5.
Extratropical forecast skill. It is expected that simulations with a more realistic MJO would also exhibit improved extratropical circulations, given the relationship between the two through atmospheric teleconnections (Zhang 2013; Vitart and Robertson 2018). To assess intraseasonal extratropical forecast skill, weekly averaged $500-\mathrm{hPa}$ geopotential height anomalies were verified in the Pacific-North American (PNA) region, an area particularly impacted by waves excited by active MJO convection 

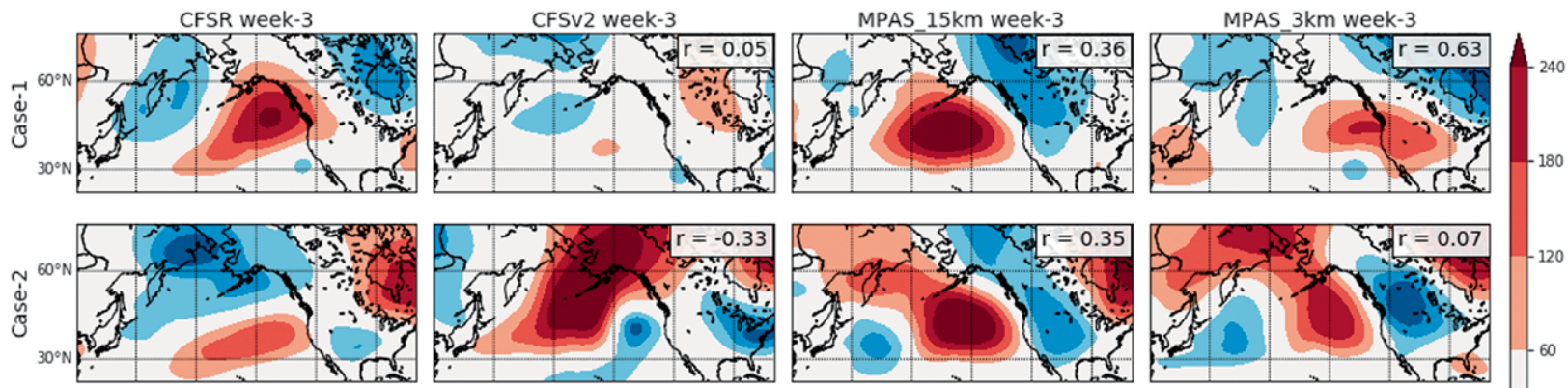

$-120$
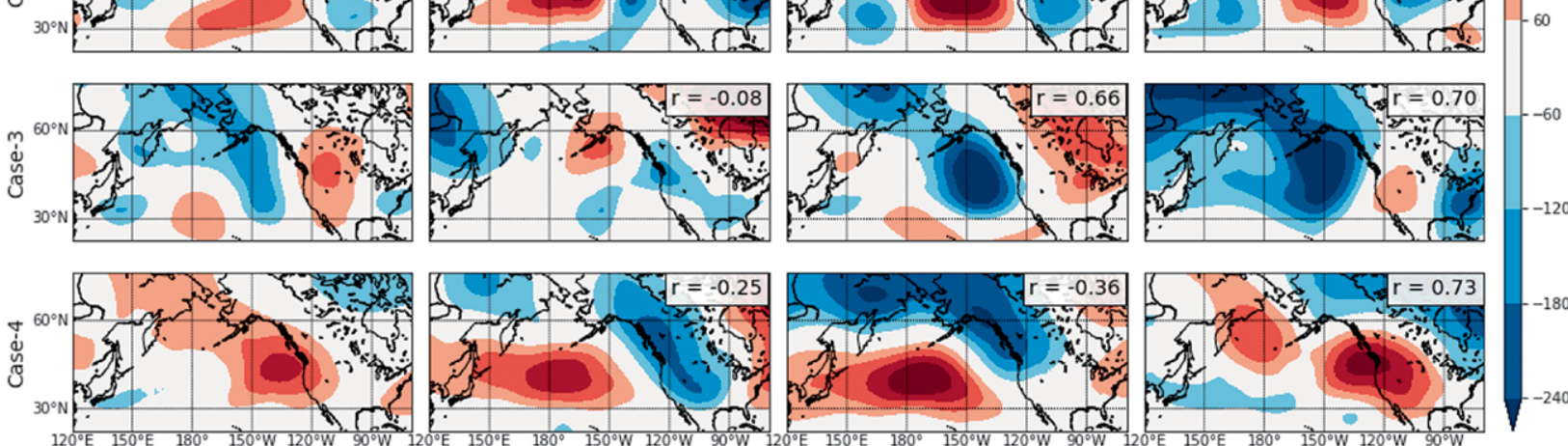

Fig. 6. Weekly averaged $500-\mathrm{hPa}$ geopotential height anomalies (m) for the third week of (first row) case I, (second row) case 2, (third row) case 3, and (fourth row) case 4 in the PNA region. These weeklong periods correspond to 6-12 Dec 20II, 22-28 Feb 2013, 16-22 Dec 2003, and 22-28 Dec 2013, respectively. Pattern correlation coefficients between each forecast (columns 2-4) and the CFSR field (first column) within the PNA domain are shown in the top right of each panel.

(Mori and Watanabe 2008). Model skill was evaluated by computing the anomaly pattern correlation between each model forecast and the associated CFSR reanalysis within the PNA region $\left(20^{\circ}-70^{\circ} \mathrm{N}\right.$, $120^{\circ} \mathrm{E}-70^{\circ} \mathrm{W}$ ). Figure 6 presents the week $3500-\mathrm{hPa}$ geopotential height anomalies for each forecast case and the corresponding CFSR analyses. For this particular forecast week, the $3-\mathrm{km}$ MPAS simulations generally provided a superior prediction of the synoptic anomalies over the western United States and eastern Pacific compared to the other model predictions, with correlation coefficients of 0.63 , $0.07,0.70$, and 0.73 , respectively, for the four cases. Of particular note is the ability of the convectionpermitting simulations to accurately predict the U.S. West Coast ridge for cases 1 and 4, in contrast to the problematic forecasts of CFSv2 and the 15km MPAS.

Anomaly correlations for all four weeks and cases are shown in Fig. 7. All three models performed well for the first forecast week, with scores above 0.9 for all four cases. For weeks 2 through 4 , however, the scores varied significantly by both case and model. In case 1 , the 3-km MPAS simulation outperformed both the $15-\mathrm{km}$ MPAS and CFSv2 for all three of these latter weeks. Case 2, on the other hand, showed a decrease in skill for weeks 2 through 4 in the $3-\mathrm{km}$ forecast compared to the $15-\mathrm{km}$ run. The case 3 scores were fairly close between the 3- and 15-km MPAS runs, with only slight improvement in weeks 2 and 3 . The largest improvement occurred in weeks 2 and 3 of case 4 , with the $3-\mathrm{km}$ MPAS maintaining correlation coefficients around 0.75 , vastly outscoring the two coarser models. The variability in skill among the various forecasts was largest in week 3 .

In summary, while there was significant variability among the four cases, the $3-\mathrm{km}$ MPAS configuration, on average, improved weekly extratropical circulation in the PNA region for weeks 2 and 3 (Fig. 7, dashed lines), with the greatest skill increases in the convection-permitting runs seen in week 3 (Fig. 6). Both MPAS configurations featured improved extratropical skill over CFSv2; though, by week 4, all three forecasts tend to lose predictive skill. The results are less dramatic if the entire Northern Hemisphere (poleward of $15^{\circ} \mathrm{N}$ ), rather than just the PNA region, is considered when calculating correlation coefficients (Fig. ES6). Only during week 3 does the $3-\mathrm{km}$ MPAS, on average, outperform the other two models' Northern Hemisphere scores.

DISCUSSION. The results from these four cases suggest that global CPMs can provide a more realistic depiction of tropical precipitation-specifically, 
its intensity and diurnal timing-when compared to coarser global models that parameterize convection. While similar results have been found in prior work with regional CPMs, it is encouraging to see replication in a global configuration. The commonly observed "too light, too frequent" precipitation problem in models with parameterized convection is a product of an oversensitivity to environmental instability (Stephens et al. 2010). Explicit convection reduces the rate at which environmental potential energy is consumed and allows greater instability buildup, resulting in more realistic, heavier rain rates

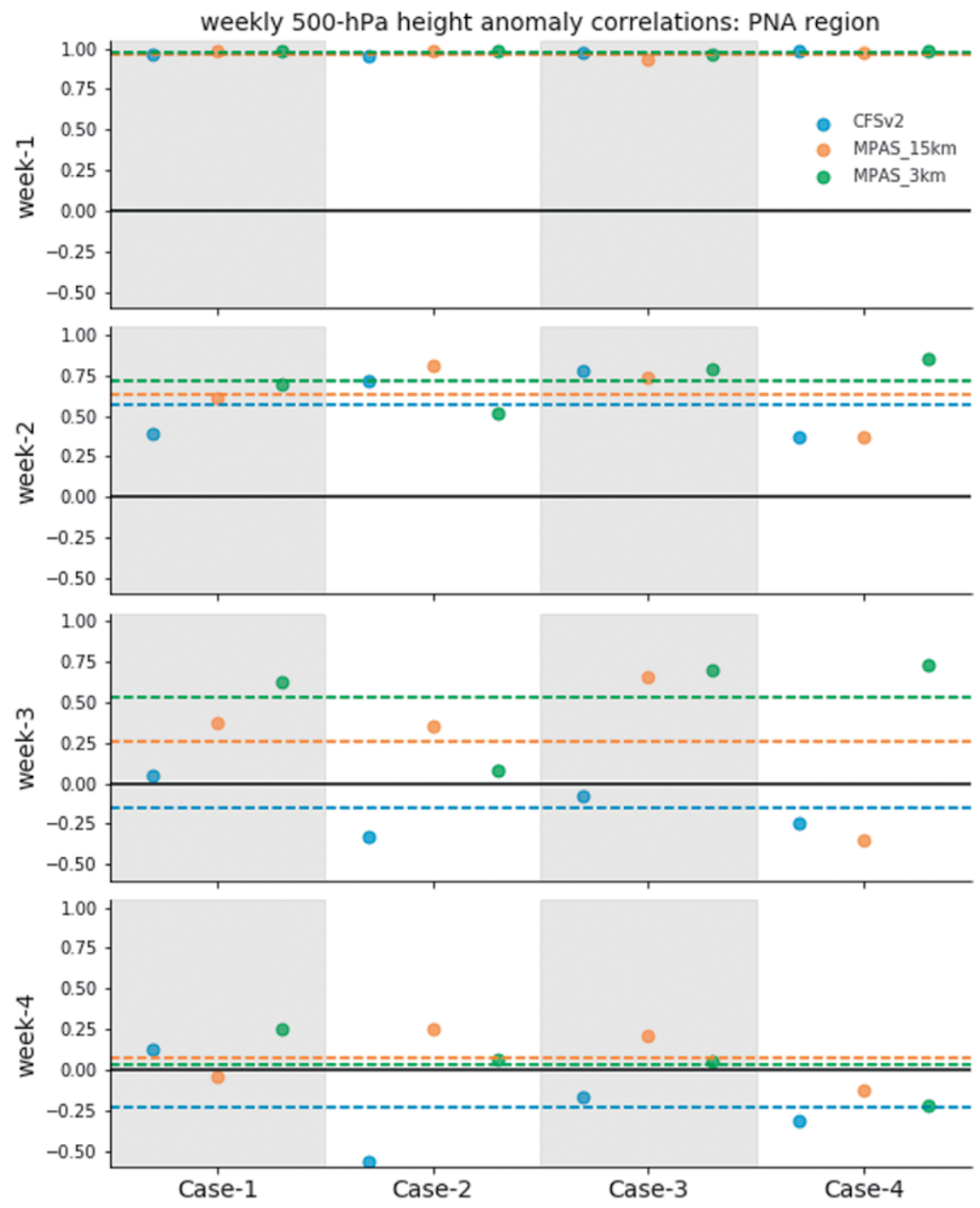

Fig. 7. Spatial pattern correlation scores for weekly averaged $500-\mathrm{hPa}$ geopotential height anomalies over the PNA region (shown in Fig. 6). The four different cases are represented in columns while the four rows indicate each week of the 28-day case period. Anomaly correlation coefficients are computed for CFSv2, MPAS_ $15 \mathrm{~km}$, and MPAS_3 km and are verified against CFSR. All weekly geopotential height anomalies are computed relative to the CFSR weekly climatology. Dashed horizontal lines represent the average anomaly correlation across all four cases for each forecast week. and improved vertical heating/moistening profiles (Holloway et al. 2012). This superior tropical convection representation in CPMs is conducive to the more accurate simulation of convectively coupled phenomena such as the MJO, which is reflected in the results shown for three of the cases described above.

Global teleconnection patterns are sensitive to both the horizontal and vertical distributions of tropical latent heating (Sardeshmukh and Hoskins 1988) in large-scale convective features like the MJO, both of which are better simulated in CPMs. In the cases shown above, global simulations with improved MJO propagation also exhibited increased skill in the PNA region of the extratropics (particularly in week 3 ), though the relationship between simulated MJO tropical convection fidelity and midlatitude circulation errors needs to be further quantified. The more skillful extratropical circulation in the 3-km MPAS runs for case 1 , case 3 , and case 4 is a promising initial result for global subseasonal prediction at convectionpermitting resolution.

Although the $3-\mathrm{km}$ case 2 experiment failed to deterministically predict the propagating $\mathrm{MJO}$ and the extratropical wave pattern, it exhibited improvement in tropical precipitation statistics similar to the other two cases. Such improvements in the model's ability to represent physical processes will, on average, yield more accurate deterministic prediction; however, even in a convection-permitting model, forecast failures can still manifest from errors in the initial state or other model deficiencies (Lorenz 1963). Unfortunately, with only four forecast cases, it is difficult to state whether the skill improvement or 
degradation in each individual case was a product of random error growth or actual physical processes. However, the increase in the average forecast skill in the $3-\mathrm{km}$ simulations does suggest that an underlying improvement in physical realism has been achieved.

It is important to note that forecast predictability is also affected by slowly evolving components of the Earth system such as sea surface temperature (Chu 1999). Our simulations kept sea surface temperatures constant to isolate the impact of atmospheric grid resolution on subseasonal prediction, and it is plausible that even greater positive impacts might be achievable with an interactive ocean. If this is true, an operational system would need to implement a coupled ocean model to harness the additional atmospheric predictability supplied by the oceanic interaction/feedbacks at subseasonal time scales.

CONCLUSIONS. This study examines the benefits of using a high-resolution global convectionpermitting model (CPM) for monthlong forecasts compared to the traditional approach of parameterizing convection in a lower-resolution model. Even without the substantial benefits of a coupled ocean model, running the Model for Prediction Across Scales (MPAS) at $3-\mathrm{km}$ resolution without convective parameterization improved the forecast precipitation statistics and enhanced multiweek predictive skill in the tropics and, to a lesser but still appreciable degree, in the extratropics. Specifically, the 3-km MPAS configuration exhibited superior propagation of the Madden-Julian oscillation (MJO) and enhanced week 3 Pacific-North American geopotential height forecast skill compared to the $15-\mathrm{km}$ control and the operational Climate Forecast System, version 2 (CFSv2), forecasts. Beyond these improvements, there are additional advances to be gained from implementing convection-permitting resolution, including more faithfully resolved terrain features and orographic precipitation, more realistic propagation of extratropical mesoscale convective systems, and improved representation of gravity wave drag produced by terrain (Davis et al. 2003; Smith et al. 2006).

This article presents an initial examination of the impacts of convection-permitting resolution on global-scale subseasonal forecasts. Ongoing and future work will examine the structure and propagation of the MJO in greater detail, more thoroughly appraise the tropical mean state at $3-\mathrm{km}$ resolution, and quantify improvements in tropical and extratropical cyclones and other synoptic structures at convection-permitting resolution. As the computational capabilities of operational forecasting centers advance, so too does the potential for utilizing global CPMs for a wide range of applications. If the positive initial results in this report regarding the use of global CPMs are duplicated in a wide range of additional cases, global CPMs may well represent an important advance for both weather and climate prediction.

ACKNOWLEDGMENTS. The authors wish to thank William Skamarock, Roy Rasmussen, and Michael Duda at the National Center for Atmospheric Research (NCAR) for their support of the project and assistance with the MPAS simulations. High-performance computing support on the Cheyenne supercomputer (https://doi.org//0.5065 /D6RX99HX) was provided by NCAR's Computational and Information Systems Laboratory, sponsored by the National Science Foundation. We also thank Professor Daehyun Kim at the University of Washington for his contributions to the tropical analysis. This research was funded by NOAA Grant NA15NWS4680023. Meteosat-7 IR and WV data were provided by NCAR/EOL under the sponsorship of the National Science Foundation (https://data.eol.ucar.edu/). Finally, the authors wish to thank three anonymous reviewers for their detailed and helpful comments on the manuscript. Authors declare no competing interests.

\section{REFERENCES}

Bechtold, P., N. Semane, and P. Lopez, 2014: Representing equilibrium and nonequilibrium convection in large-scale models. J. Atmos. Sci., 71, 734-753, https:// doi.org/10.1175/JAS-D-13-0163.1.

Brunet, G., and Coauthors, 2010: Collaboration of the weather and climate communities to advance subseasonal-to-seasonal prediction. Bull. Amer. Meteor. Soc., 91, 1397-1406, https://doi.org/10.1175 /2010BAMS3013.1.

Chu, P. C., 1999: Two kinds of predictability in the Lorenz system. J. Atmos. Sci., 56, 1427-1432, https:// doi.org/10.1175/1520-0469(1999)056<1427:TKOPIT $>2.0 . \mathrm{CO} ; 2$.

Davis, C. A., K. W. Manning, R. E. Carbone, S. B. Trier, and J. D. Tuttle, 2003: Coherence of warm-season continental rainfall in numerical weather prediction models. Mon. Wea. Rev., 131, 2667-2679, https://doi .org/10.1175/1520-0493(2003)131<2667:COWCRI $>2.0 . \mathrm{CO} ; 2$.

Gottschalck, J., P. E. Roundy, C. J. Schreck III, A. Vintzileos, and C. Zhang, 2013: Large-scale atmospheric and oceanic conditions during the 2011-12 DYNAMO field campaign. Mon. Wea. Rev., 141, 41734196, https://doi.org/10.1175/MWR-D-13-00022.1. 
Hirons, L. C., N. P. Klingaman, and S. J. Woolnough, 2018: The impact of air-sea interactions on the representation of tropical precipitation extremes. J. Adv. Model. Earth Syst., 10, 550-559, https://doi .org/10.1002/2017MS001252.

Holloway, C. E., S. J. Woolnough, and G. M. S. Lister, 2012: Precipitation distributions for explicit versus parametrized convection in a large-domain high-resolution tropical case study. Quart. J. Roy. Meteor. Soc., 138, 1692-1708, https://doi.org/10.1002 /qj.1903.

Inoue, R., M. Satoh, H. Miura, and B. Mapes, 2008: Characteristics of cloud size of deep convection simulated by a global cloud resolving model over the western tropical Pacific. J. Meteor. Soc. Japan, 86A, 1-15, https://doi.org/10.2151/jmsj.86A.1.

Kerns, B. W., and S. S. Chen, 2014: ECMWF and GFS model forecast verification during DYNAMO: Multiscale variability in MJO initiation over the equatorial Indian Ocean. J. Geophys. Res. Lett., 119, 3736-3755, https://doi.org/10.1002/2013JD020833.

Kim, H.-M., P. J. Webster, V. E. Toma, and D. Kim, 2014: Predictability and prediction skill of the MJO in two operational forecasting systems. J. Climate, 27, 53645378, https://doi.org/10.1175/JCLI-D-13-00480.1.

Li, S., and A. W. Robertson, 2015: Evaluation of submonthly precipitation forecast skill from global ensemble prediction systems. Mon. Wea. Rev., 143, 2871-2889, https://doi.org/10.1175/MWR-D-14 -00277.1 .

Lin, J.-L., and Coauthors, 2006: Tropical intraseasonal variability in 14 IPCC AR4 climate models. Part I: convective signals. J. Climate, 19, 2665-2690, https:// doi.org/10.1175/JCLI3735.1.

Lorenz, E. N., 1963: Deterministic nonperiodic flow. J. Atmos. Sci., 20, 130-141, https://doi.org/10.1175/1520 -0469(1963)020<0130:DNF>2.0.CO;2.

Madden, R. A., and P. R. Julian, 1972: Description of global-scale circulation cells in the tropics with a 40 50 day period. J. Atmos. Sci., 29, 1109-1123, https:// doi.org/10.1175/1520-0469(1972)029<1109:DOGSCC $>2.0 . \mathrm{CO} ; 2$.

Miura, H., M. Satoh, T. Nasuno, A. T. Noda, and K. Oouchi, 2007: A Madden-Julian oscillation event realistically simulated by a global cloud-resolving model. Science, 318, 1763-1765, https://doi.org /10.1126/science.1148443.

Mori, M., and M. Watanabe, 2008: The growth and triggering mechanisms of the PNA: A MJO-PNA coherence. J. Meteor. Soc. Japan, 86, 213-236, https:// doi.org/10.2151/jmsj.86.213.

Prein, A. F., and Coauthors, 2015: A review on regional convection-permitting climate modeling: Demonstrations, prospects, and challenges. Rev. Geophys., 53, 323-361, https://doi.org/10.1002/2014RG000475.

Saha, S., and Coauthors, 2014: The Climate Forecast System version 2. J. Climate, 27, 2185-2208, https:// doi.org/10.1175/JCLI-D-12-00823.1.

Sardeshmukh, P. D., and B. J. Hoskins, 1988: The generation of global rotational flow by steady idealized tropical divergence. J. Atmos. Sci., 45, 1228-1251, https:// doi.org/10.1175/1520-0469(1988)045<1228:TGOG $\mathrm{RF}>2.0 . \mathrm{CO} ; 2$.

Sato, T., H. Miura, M. Satoh, Y. N. Takayabu, and Y. Wang, 2009: Diurnal cycle of precipitation in the tropics simulated in a global cloud-resolving model. J. Climate, 22, 4809-4826, https://doi.org/10.1175 /2009JCLI2890.1.

Seo, K.-H., W. Wang, J. Gottschalck, Q. Zhang, J. E. Schemm, W. R. Higgins, and A. Kumar, 2009: Evaluation of MJO forecast skill from several statistical and dynamical forecast models. J. Climate, 22, 2372-2388, https://doi.org/10.1175/2008JCLI2421.1.

Skamarock, W. C., J. B. Klemp, M. G. Duda, L. D. Fowler, S.-H. Park, and T. D. Ringler, 2012: A multiscale nonhydrostatic atmospheric model using centroidal Voronoi tessellations and C-grid staggering. Mon. Wea. Rev., 140, 3090-3105, https://doi.org/10.1175 /MWR-D-11-00215.1.

Smith, S. A., J. D. Doyle, A. R. Brown, and S. Webster, 2006: Sensitivity of resolved mountain drag to model resolution for MAP case-studies. Quart. J. Roy. Meteor. Soc., 132, 1467-1487, https://doi.org/10.1256 /qj.05.67.

Stephens, G., and Coauthors, 2010: Dreary state of precipitation in global models. J. Geophys. Res., 115, D24211, https://doi.org/10.1029/2010JD014532.

Vitart, F., 2014: Evolution of ECMWF sub-seasonal forecast skill scores. Quart. J. Roy. Meteor. Soc., 140, 1889-1899, https://doi.org/10.1002/qj.2256.

_ 2017: Madden-Julian oscillation prediction and teleconnections in the S2S database. Quart. J. Roy. Meteor. Soc., 143, 2210-2220, https://doi.org/10.1002/qj.3079.

— , and A. Robertson, 2018: The sub-seasonal to Seasonal Prediction Project (S2S) and the prediction of extreme events. npj Climate Atmos. Sci., 1, 3, https:// doi.org/10.1038/s41612-018-0013-0.

Wallace, J. M., and D. S. Gutzler, 1981: Teleconnections in the geopotential height field during the Northern Hemisphere winter. Mon. Wea. Rev., 109, 784-812, https://doi.org/10.1175/1520-0493(1981)109<0784:TI $\mathrm{TGHF}>2.0 . \mathrm{CO} ; 2$.

Weaver, S.-J., W. Wang, M. Chen, and A. Kumar, 2011: Representation of MJO variability in the NCEP Climate Forecast System. J. Climate, 24, 4676-4694, https://doi.org/10.1175/2011JCLI4188.1. 
Weber, N., and C. Mass, 2017: Evaluating CFSv2 subseasonal forecast skill with an emphasis on tropical convection. Mon. Wea. Rev., 145, 3795-3815, https:// doi.org/10.1175/MWR-D-17-0109.1.

Weisman, M. L., W. C. Skamarock, and J. B. Klemp, 1997: The resolution dependence of explicitly modeled convective systems. Mon. Wea. Rev., 125, 527-548, https://doi.org/10.1175/1520-0493(1997)125<0527:TR DOEM $>2.0 . \mathrm{CO} ; 2$.
Zhang, C., 2013: Madden-Julian oscillation: Bridging weather and climate. Bull. Amer. Meteor. Soc., 94, 18491870, https://doi.org/10.1175/BAMS-D-12-00026.1.

Zhang, C., and Y. Wang, 2017: Projected future changes of tropical cyclone activity over the western North and South Pacific in a $20-\mathrm{km}$-mesh regional climate model. J. Climate, 30, 5923-5941, https://doi .org/10.1175/JCLI-D-16-0597.1.

\section{A Scientific Peak: How Boulder} Became a World Center for Space and Atmospheric Science

\section{Joseph P. Bassi}

nce a Wild West city tucked between the Rocky Mountains and the Great Plains, Boulder is now home to some of the biggest names in science, including NCAR, NOAA, and NIST.

Why did big science come to Boulder? How did Boulder become the research mecca it is today?

A Scientific Peak is a fascinating history that introduces us to a wide variety of characters, such as Walter Orr Roberts, and the serendipitous brew of politics, pas. sion, and sheer luck that, during the post-WWII and Cold War eras, transformed this "scientific Siberia" into one of America's smartest cities.

(C) 2015, 264 pages, paperback

print ISBN: 978-1-935704-85-0 eISBN: 978-1-940033-89-1 List price: $\$ 35$ AMS Member price: $\$ 25$
Joseph P. Bassi

\section{A SCIENTIFIC PEAK}

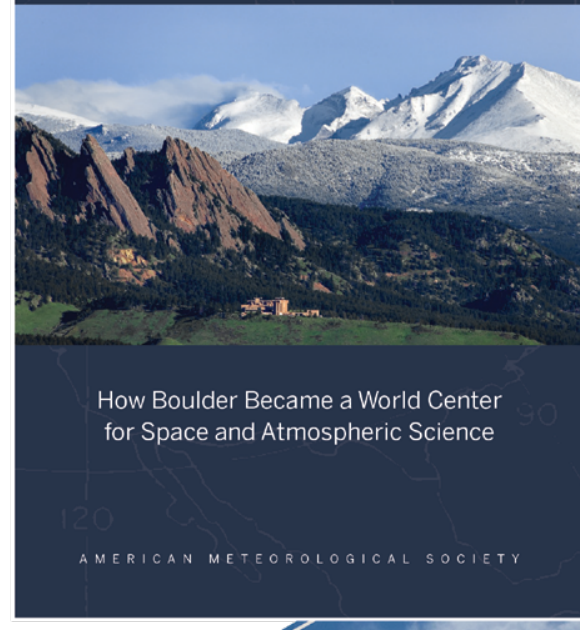



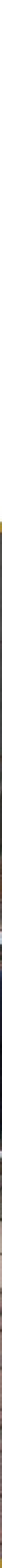

\section{As the next generation of scientific leaders, students can play a role in helping lift AMS to new heights.}

Donate to the AMS 100th Anniversary Campaign by joining the Student Leadership Circle. Your contribution of \$20.19 will help raise funds to support the Student Conference, travel grants, and other AMS initiatives.

\section{ametsoc.org/give}

